\title{
Recipe for Predicting Strong Ground Motion from Crustal Earthquake Scenarios
}

\author{
KoJIRo Irikura $^{1}$ and Hiroe MiYaKe ${ }^{2}$
}

\begin{abstract}
We developed a recipe for predicting strong ground motions based on a characterization of the source model for future crustal earthquakes. From recent developments of waveform inversion of strong motion data used to estimate the rupture process, we have inferred that strong ground motion is primarily related to the slip heterogeneity inside the source rather than average slip in the entire rupture area. Asperities are characterized as regions that have large slip relative to the average slip on the rupture area. The asperity areas, as well as the total rupture area, scale with seismic moment. We determined that the areas of strong motion generation approximately coincide with the asperity areas. Based on the scaling relationships, the deductive source model for the prediction of strong ground motions is characterized by three kinds of parameters: outer, inner, and extra fault parameters. The outer fault parameters are defined as entire rupture area and total seismic moment. The inner fault parameters are defined as slip heterogeneity inside the source, area of asperities, and stress drop on each asperity based on the multipleasperity model. The pattern of rupture nucleation and termination are the extra fault parameters that are related to geomorphology of active faults. We have examined the validity of the earthquake sources constructed by our recipe by comparing simulated and observed ground motions from recent inland crustal earthquakes, such as the 1995 Kobe and 2005 Fukuoka earthquakes.
\end{abstract}

Key words: Recipe, strong ground motion prediction, crustal earthquake, characterized source model, hybrid method.

\section{Introduction}

High-quality strong ground motions have been recorded from recent large earthquakes in Japan, such as the 1995 Kobe, 2000 Tottori, 2004 Chuetsu, 2005 Fukuoka, 2007 Chuetsu-oki earthquakes, and others. Accumulations of strong ground motions have provided us very important knowledge about rupture

1 Aichi Institute of Technology and Kyoto University, 1247 Yachigusa, Yakusa, Toyota, Aichi 470-0392, Japan. E-mail: irikura@geor.or.jp

2 Earthquake Research Institute, University of Tokyo, 1-1-1 Yayoi, Bunkyo-ku, Tokyo 113-0032, Japan. processes of earthquakes, propagation-path and siteamplification effects, and the relation between ground motion and damage. Predicting strong ground motion is one of the critical factors for mitigating disasters caused by future earthquakes.

So far, most strong motion predictions in earthquake hazard analyses have been made using empirical attenuation-distance curves for peak ground acceleration (PGA), peak ground velocity (PGV), and response spectra, in which the source information is defined exclusively by the seismic magnitude and fault 7 geometry. However, damaging ground motions are sometimes characterized by the rupture directivity pulses as observed during the 1992 Landers and 1995 Kobe earthquakes, and these are crucial issues for predicting ground motion time histories for the worst earthquake scenarios. This study focuses on the broadband ground motion prediction based source modeling and Green's functions based on velocity structures.

From recent developments based on waveform inversion of strong motion data for estimating the rupture process during large earthquakes, we now understand that strong ground motion is related to the slip heterogeneity rather than the average slip over the entire rupture area. Somerville et al. (1999) characterized asperities as regions on the fault that have large slip relative to the average slip of the rupture area. They also found that the asperity areas, as well as the entire rupture areas, scale with the total seismic moment. MiYAKe et al. (2001, 2003) found that the strong motions were generated in areas where the stresses being released were the largest that approximately coincided with the asperity areas.

Based on two kinds of scaling relationships-one for the entire rupture area and the other for the asperity areas with respect to the total seismic moment-we found that the source model for the prediction of strong ground motions can be characterized by three kinds of 
parameters: outer, inner, and extra fault parameters. The outer fault parameters are conventional parameters characterizing the size of an earthquake, such as the rupture area and seismic moment, which give an overall picture of the source fault. The inner fault parameters, newly introduced in this study, define the slip heterogeneity within the seismic source. These parameters include the combined area of the asperities and the stress drop of each asperity, which have a major influence on the strong ground motions. The extra fault parameters are used to characterize the rupture nucleation and termination, such as the starting point and propagation pattern of the rupture. From a combination of the outer, inner and extra fault parameters we developed a "recipe" for predicting strong ground motions for future large earthquakes (IRIKURA AND MiYAKe 2001; IRIKURA, 2004).
The 'recipe' for strong motion prediction is shown in Fig. 1. The strong ground motions from a scenario earthquake are evaluated based on comprehensive information about (1) monitoring of seismic activity and field surveys of active faults around the target areas, (2) observation of strong ground motions, and (3) exploration of velocity structures in targeted areas. There are two important factors for predicting strong ground motion: one is source modeling for each earthquake scenario and the second is estimation of the Green's functions from source to site. Source models for specific earthquakes are derived from analysis of (1) and (2); the Green's functions are estimated using analysis of (2) and (3). Then, ground motions are predicted using the source models and the Green's functions. The validity of the results is determined by comparing the historical data with

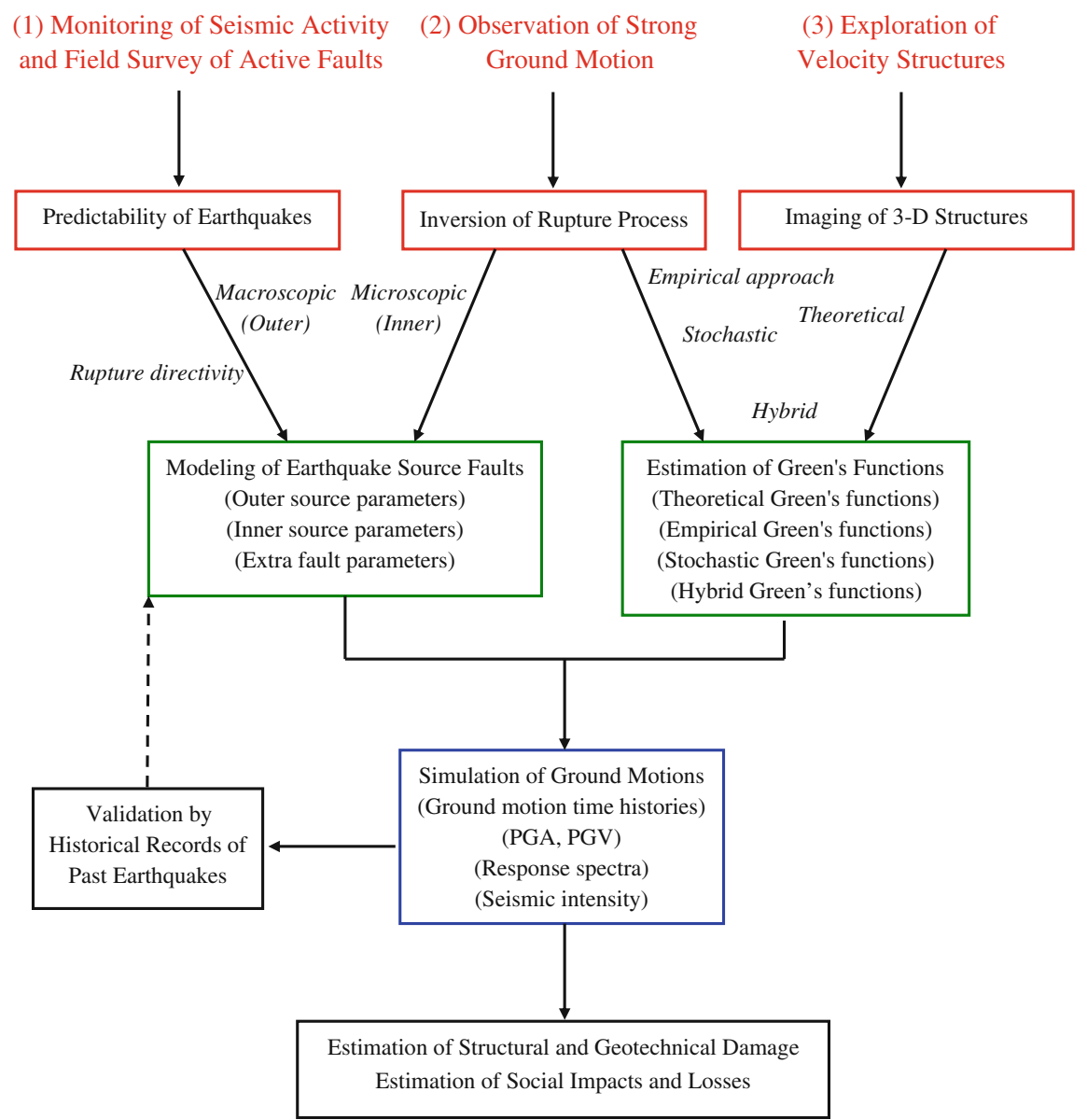

Figure 1

Framework of predicting strong ground motions for crustal earthquake scenarios 
predicted motions. Using the 'recipe' for future large earthquakes, we can provide earthquake engineers, emergency response personnel and other government and private officials with ground motion estimates that will allow them to take the appropriate action.

\section{Characterized Source Model}

As already described, the strong ground motions are related to the regions of slip heterogeneity rather than the entire rupture area and total seismic moment. Based on the source characterization of SOMERvILLE et al. (1999), we have proposed a characterized source model consisting of a few asperities with large slip and background region with less slip (MIYAKE et al., 2003). An example of such a characterized source for the 1997 Kagoshima, Japan, earthquake $\left(M_{\mathrm{w}} 6.0\right)$ is shown in Fig. 2. The source process was estimated by Miyakoshi et al. (2000). The characterized source model with an asperity inside the rupture area as defined by SOMERviLLe et al. (1999) is
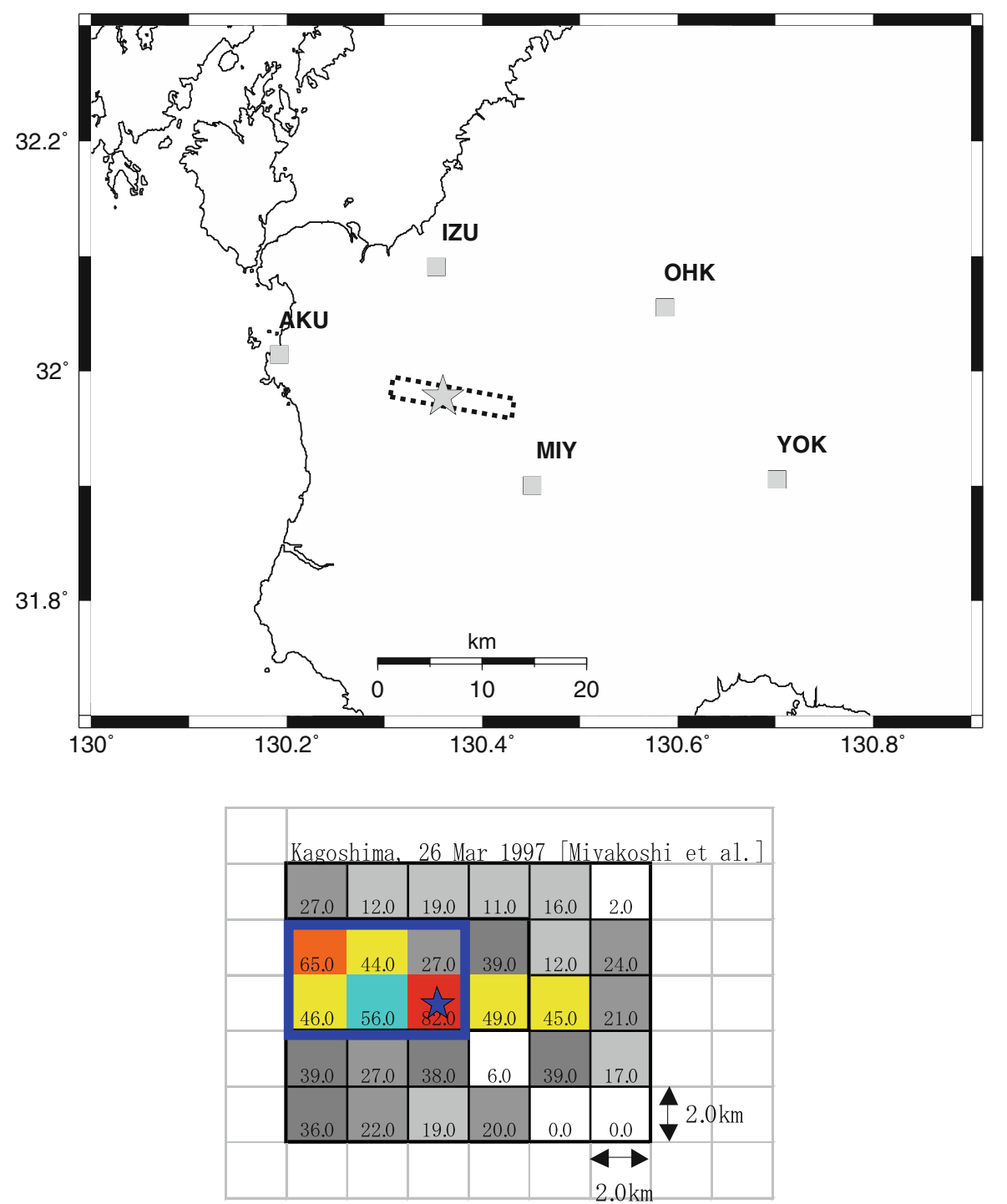

Figure 2

Upper Fault model of the 1997 Kagoshima earthquake and stations for ground motion simulation. Star indicates the rupture starting point. Lower characterized source model for the 1997 Kagoshima earthquake. Rectangular region with a bold line show the area of the asperity. Star indicates the rupture starting point 
shown in the lower part of Fig. 2. Simulated ground motions using this model agree well with the observed records (Fig. 3). As shown, the areas that generate strong motion approximately coincide with the asperity areas.

We here introduce the idea of source characterization for predicting strong ground motion based on the multiple-asperity source model, which is given as an extension of a single-asperity source model by DAS and Kostrov (1986). The stress and slip fields for a single-crack and a single-asperity model are summarized in Fig. 4. Once distribution of the stress field is characterized and a friction law is specified, a dynamic simulation provides the slip distribution. We regard the relationship between the characterized source model and the slip distribution from waveform inversion as the relationship between stress and slip fields for the single-asperity model.

The size and stress drop of asperity are significant parameters for predicting strong ground motion. Using the stress drop for a single-crack (circular) model $\Delta \bar{\sigma}_{\mathrm{c}}$ (Eq. 1) by Eshelby (1957), the stress drop of the asperity $\Delta \sigma_{\mathrm{a}}$ is estimated following MADARIAGA (1979) or DAs and Kostrov (1986) and given in Eq. 2.

$$
\begin{gathered}
\Delta \bar{\sigma}_{\mathrm{c}}=\frac{7}{16} \cdot \frac{M_{0}}{R^{3}} \\
\Delta \sigma_{\mathrm{a}}=\frac{7}{16} \cdot \frac{M_{0}}{R r^{2}}=\Delta \bar{\sigma}_{\mathrm{c}} \cdot \frac{S}{S_{\mathrm{a}}}
\end{gathered}
$$

where $M_{0}, S$, and $S_{\text {a }}$ are seismic moment, rupture area, and asperity area; $R$ and $r$ correspond to the radii of $S$ and $S_{\text {a }}$, respectively.

Some characterized source models consist of multiple asperities. Stress drop on each asperity is derived based on a multiple-asperity model, which is given as an extension of a single-asperity model by Das and Kostrov (1986). When we assume the multiple-asperity model with $n$ asperities, the total seismic moment is derived by following BOATWRIGHT (1988), as long as the combined area of asperities is constant.

$$
\begin{gathered}
M_{0}=\sum_{k=1}^{n} \frac{16}{7} \cdot \Delta \sigma_{\mathrm{a}} \cdot R r_{k}^{2}=\frac{16}{7} \cdot \Delta \sigma_{\mathrm{a}} \cdot R \sum_{k=1}^{n} r_{k}^{2} \\
=\frac{16}{7} \cdot \Delta \sigma_{\mathrm{a}} \cdot R r^{2} \\
\quad r=\sqrt{\sum_{k=1}^{n} r_{k}^{2}}
\end{gathered}
$$

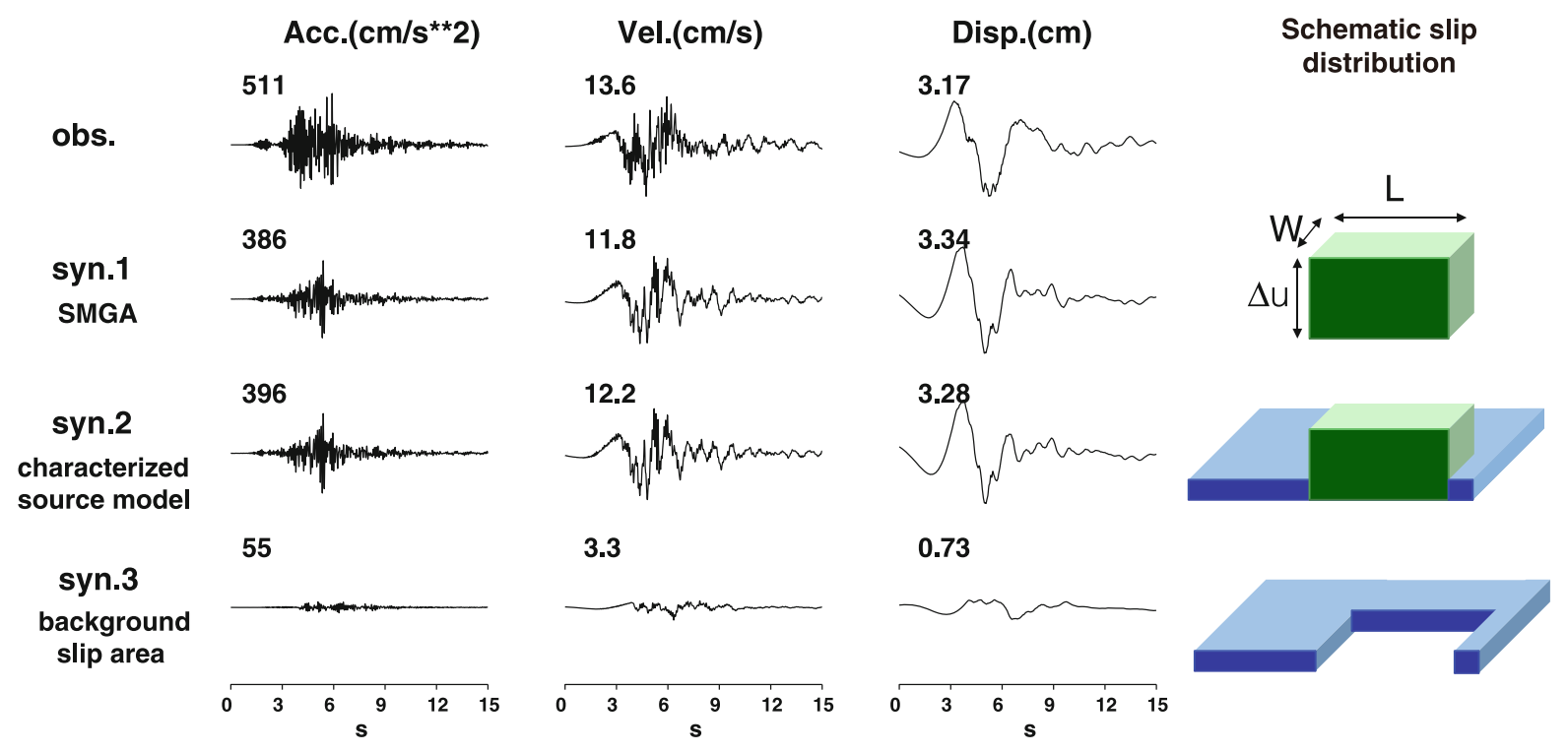

Figure 3

Comparison between observed and simulated ground motions using a characterized source model (after MIYAKE et al., 2003) 
(a) Single-Asperity Model
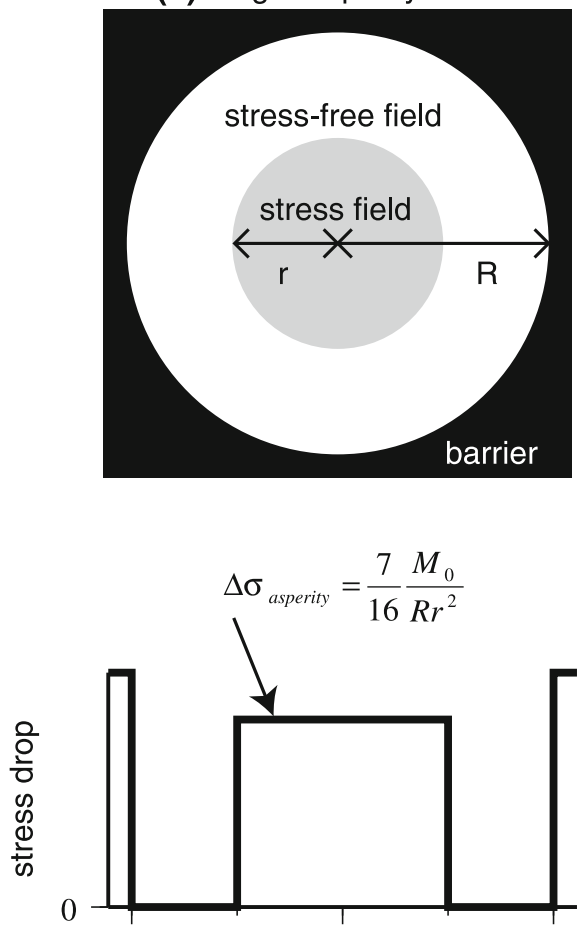

$D(x)=?$

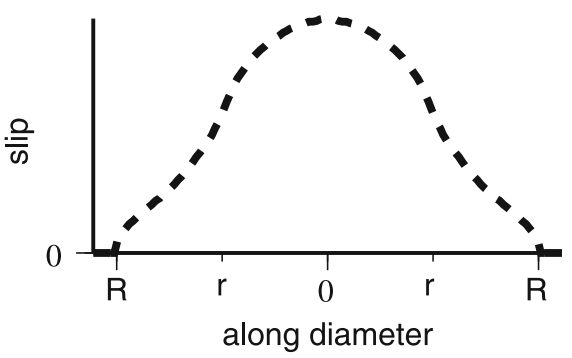

(b) Single-Crack Model
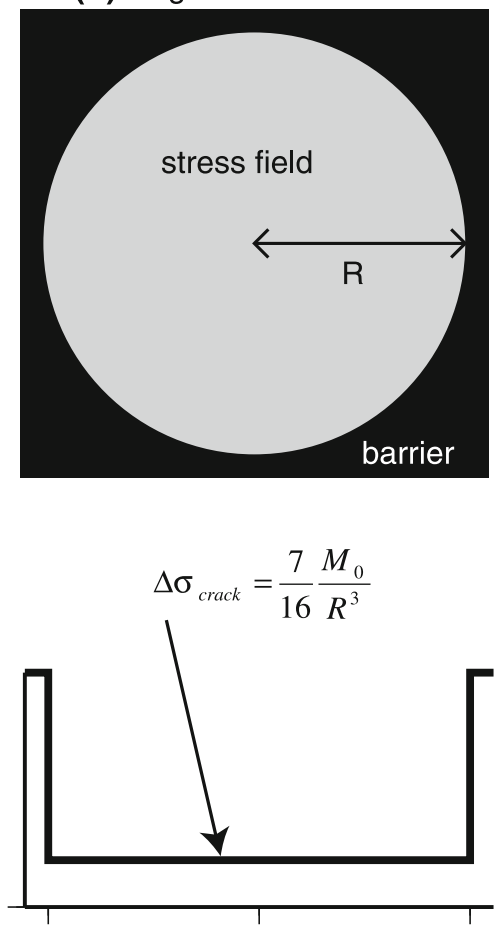

$D(x)=\frac{24}{7 \pi} \frac{\Delta \sigma_{\text {crack }}}{\mu} \sqrt{R^{2}-x^{2}}$

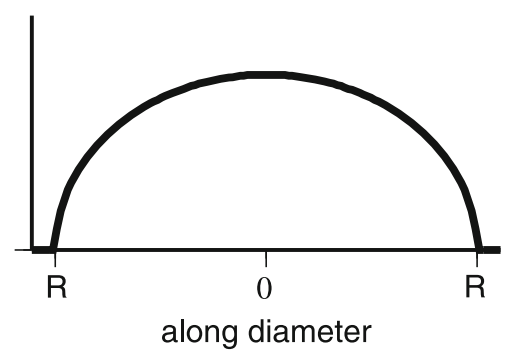

Figure 4

Two earthquakes with the same seismic moment presented as a a single-asperity model and $\mathbf{b}$ a single-crack model. Expected slip distribution $D(x)$ for a single-asperity and single-crack model (Eshelby, 1957) is indicated for a stress drop given as $\Delta \sigma_{\text {asperity }}$ and $\Delta \sigma_{\text {crack }}$

$$
\Delta \sigma_{\mathrm{a}}=\frac{7}{16} \cdot \frac{M_{0}}{R r^{2}}
$$

Equation 5 shows the stress drop on asperities is the same regardless of the single- or multiple-asperity source models as long as the combined area of asperities is constant. It suggests that the source scaling for the outer and inner fault parameters by SOMERVILLE et al. (1999) indicating constant stress drop on asperities (here, 10.5 MPa) over the wide range of seismic moment.

\section{Scaling Relationships of Fault Parameters}

Most of the difficulties in predicting strong ground motion are related to characterizing the source models for future earthquakes. To determine 
the source models, fundamental relationships controlling fault parameters, i.e. scaling relations, must be clearly defined. Conventional scaling relations for the fault parameters, such as the fault length and average slip on the fault based on the seismic magnitude, are mostly determined geologically from surface offsets and geophysically from forward source modeling, using teleseismic data and geodetic data (e.g., Kanamori and Anderson, 1975). Those data are only available for very long period motions and are insufficient for the near-source strong motions dominating short period motions of less than $1 \mathrm{~s}$, which are of interest to engineers. The scaling of the fault parameters based on the waveform inversion results for the source process using the strong motion data gives a clue on how to solve this problem. We

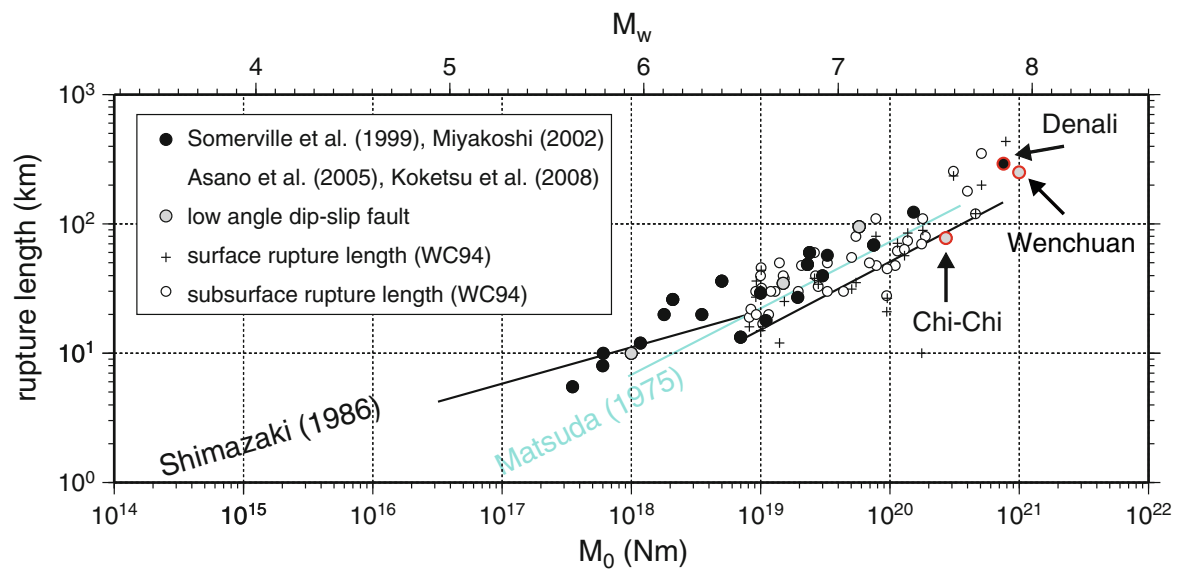

Figure 5

Empirical relationships between seismic moment and fault length for inland crustal earthquakes. The relationships by MATSUDA (1975) and SHIMAZAKI (1986) are compared for reference. The parameters for recent mega-scale crustal earthquakes, the 1999 Chi-Chi, 2002 Denali, and 2008 Wenchuan earthquakes are indicated

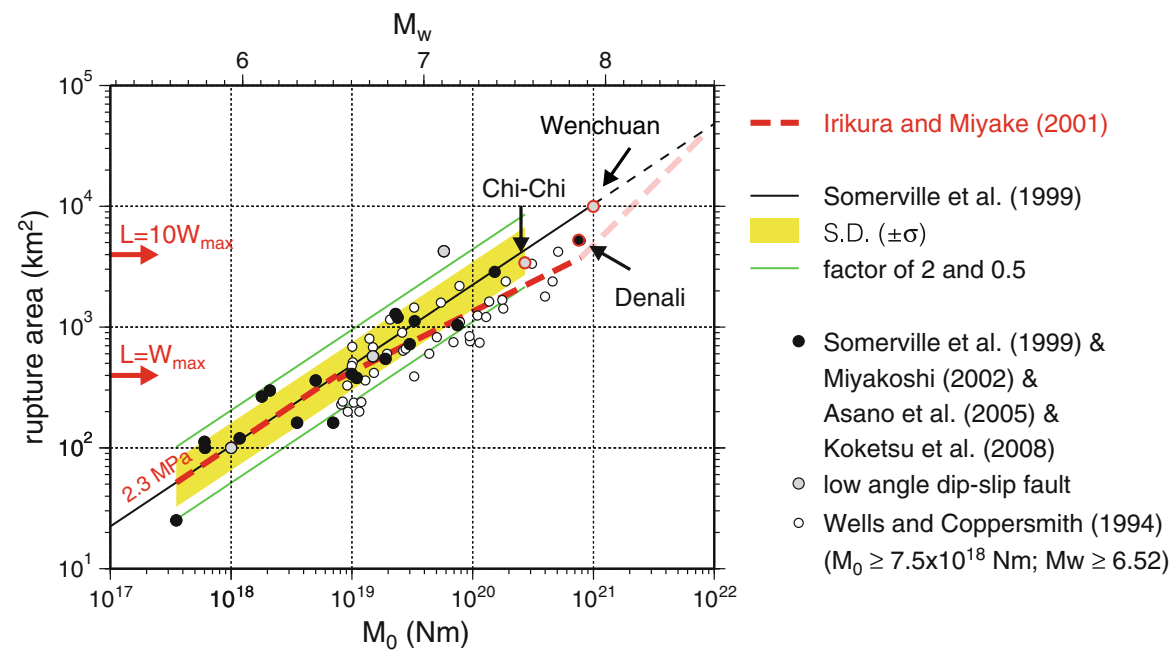

Figure 6

Empirical relationships between seismic moment and rupture area for inland crustal earthquakes. Red broken lines are the three-stage scaling relationships proposed by our studies (after IrIKURA and MiYaKe, 2001; IRIKURA et al., 2004) 
found two kinds of scaling relationships, one for the outer and the other for the inner fault parameters.

\subsection{Outer Fault Parameters}

The scaling for the outer fault parameters, i.e., the relationships between the seismic moment and fault length and between the seismic moment and rupture area, for inland crustal earthquakes are summarized as shown in Figs. 5 and 6 (IrIKURA et al., 2004). The relationship by MATSUDA (1975) is available for most earthquakes with seismic moment greater than $10^{19} \mathrm{Nm}$. The relationship by SHIMAZAKI (1986) corresponds to shorter rupture lengths for a given seismic moment, which is probably appropriate for a low-angle reverse fault such as the 1999 Chi-Chi earthquake.

The rupture area is plotted against seismic moment in Fig. 6. For earthquakes with a relatively small seismic moment (less than $10^{19} \mathrm{Nm}$ ), the total fault area $S$ seems to follow the self-similar scaling relation, with a constant static stress drop proportional to the two-thirds power of the seismic moment $M_{0}$. For earthquakes with seismic moment greater than $10^{19} \mathrm{Nm}$, the scaling tends to depart from the self-similar model (IRIKURA and MiYaKe, 2001); this
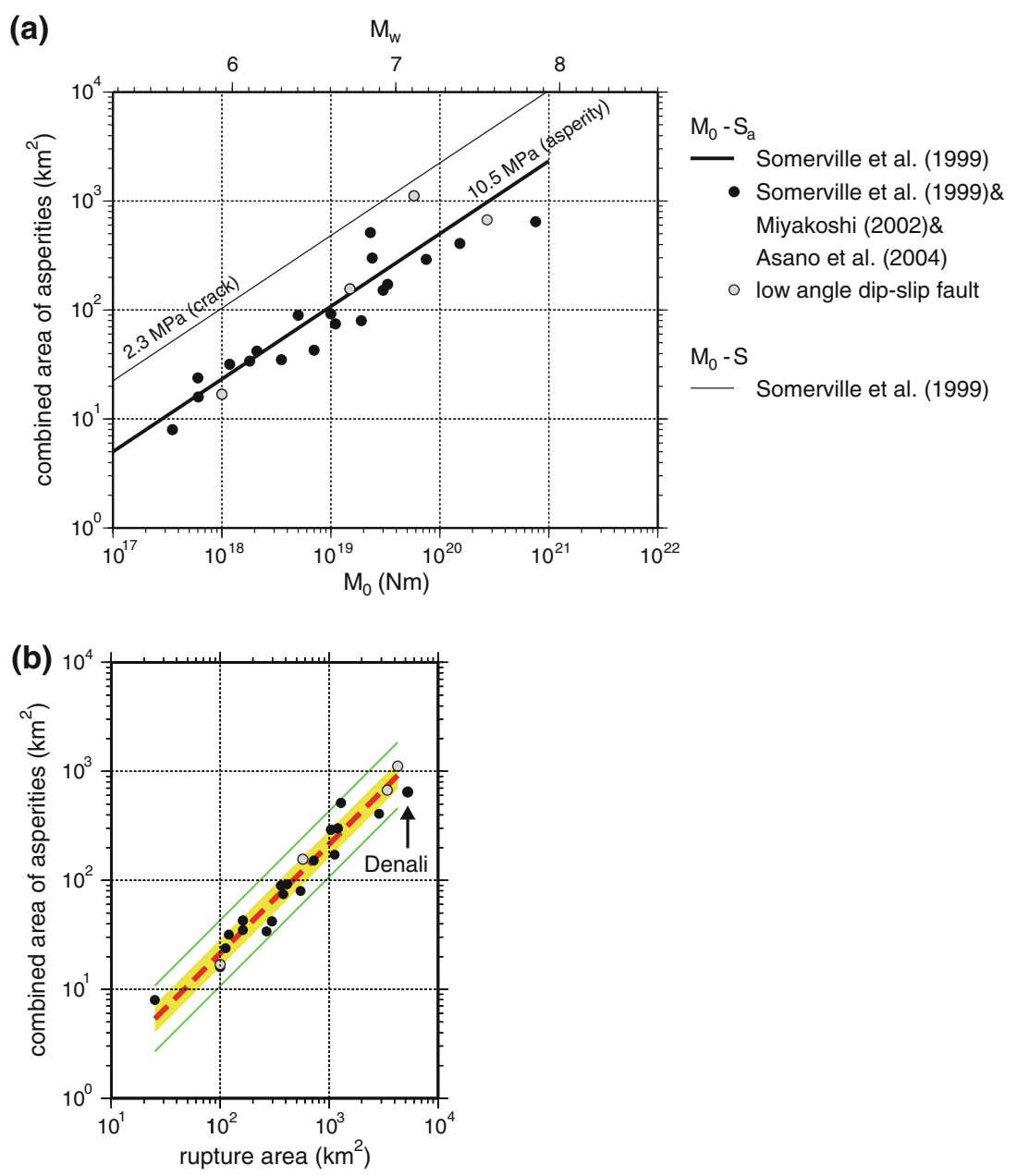

Figure 7

a Empirical relationships between seismic moment and combined area of asperities for inland crustal earthquakes. b Empirical relationships between combined area of asperities and total rupture area for inland crustal earthquakes (after IRIKURA and MiYAKE, 2001). Shaded areas represent $\pm \sigma$ (standard deviation). The thin solid lines show a factor of 2 and $1 / 2$ for the average. The database obtained by waveform inversions is from Somerville et al. (1999) and MiYaKoshi (2002) 
departure corresponds to the saturation of the fault width in a finite-size seismogenic zone. Such a twostage scaling relationship was also found by HANKS and BAKUn (2002). We added one more stage for extra large earthquakes having a seismic moment greater than $10^{21} \mathrm{Nm}$, based on the idea of ScHOLZ (2002), changing from an $L$-model into a $W$-model. As shown by the broken lines in Fig. 6, the scaling relationships in this study assume that the fault width saturates at $20 \mathrm{~km}$.

The parameters for recent mega-scale crustal earthquakes, the 1999 Chi-Chi, 2002 Denali, and 2008 Wenchuan earthquakes seem to have a little smaller area for their seismic moment. These data may suggest that the third stage, mentioned above, might be shifted to lower seismic moment. The lowangle dip slip faults of the 1999 Chi-Chi and 2008 Wenchuan earthquakes seem to support SomerviLLE et al. (1999); on the other hand, the strike slip fault of the 2002 Denali earthquake seems to support IRIKURA and MiYake (2001).

\subsection{Inner Fault Parameters}

Strong ground motions are more influenced by the inner fault parameters representing the slip heterogeneity than by the outer fault parameters (MIYAKE et al., 2001, 2003). The empirical relationship between the seismic moment $M_{0}$ and combined area of asperities and between the rupture area $S$, as the outer fault parameter is shown in Fig. 7a; the empirical relation between the combined area of the asperities $S_{\mathrm{a}}$, as the inner fault parameter, and total rupture area is shown in Fig. 7b (IRIKURA and MiYaKe, 2001). The combined area of asperities clearly increases with the seismic moment for both inland and subduction earthquakes. The ratio $S_{\mathrm{a}} / S$ seems to be constant regardless of the rupture area, with a value of about 0.22 for an inland earthquake and about 0.25 for a subduction earthquake. The stress drop on the asperities $\Delta \sigma_{\mathrm{a}}$ is derived by multiplying the average stress drop over the fault $\Delta \bar{\sigma}_{\mathrm{c}}$ by the ratio of the total rupture area $S$ to the asperity area $S_{\text {a }}$ (e.g., MAdARIAGA, 1979).

$$
\Delta \sigma_{\mathrm{a}}=\Delta \bar{\sigma}_{\mathrm{c}} \cdot \frac{S}{S_{\mathrm{a}}}
$$

Another empirical-relationship related to the inner source parameters is shown in Fig. 8. The relationship between the seismic moment $M_{0}$ and the amplitude of the acceleration source spectral level $A_{0}$ was originally found by DAN et al. (2001) and later confirmed by others (MORIKAwa and FuJIWARA, 2003; SATOH, 2004).

$$
A_{0}^{a}\left(\mathrm{Nm} / \mathrm{s}^{2}\right)=2.46 \times 10^{10} \times\left(M_{0}(\mathrm{Nm}) \times 10^{7}\right)^{1 / 3}
$$

The acceleration level $A_{0}$ was theoretically related to the combined asperity areas and the stress drop in

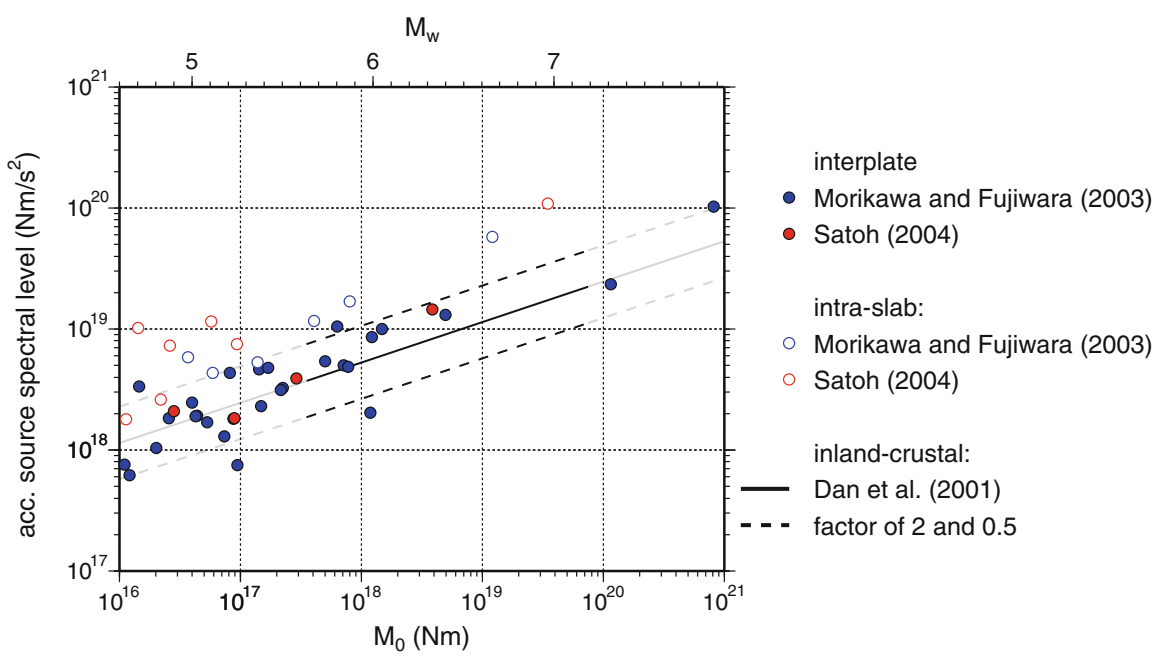

Figure 8

Empirical relationship between seismic moment and acceleration source-spectral level 
the asperities for a circular asperity by MADARIAGA (1977).

$$
A_{0}^{a}=4 \sqrt{\pi} \beta v_{r} \Delta \sigma_{\mathrm{a}} \sqrt{S_{\mathrm{a}}}
$$

By putting together the relationships $A_{0} \propto M_{0}^{1 / 3}$ and $A_{0}^{a} \propto M_{0}^{1 / 3}$, which were obtained empirically (IRIKURA and MiYAKe, 2001), the combined area of the asperities can be estimated as follows.

$$
S_{\mathrm{a}}=\left(\frac{7 \pi^{2}}{4} \beta v_{R}\right)^{2} \cdot \frac{\left(M_{0}\right)^{2}}{S \cdot\left(A_{0}^{a}\right)^{2}}
$$

In this case the stress drop is also given by 6 .

\subsection{Constraints on Average Slip of Asperities from Dynamic Simulations}

We here introduce quasi-dynamic source modeling to examine the relation between average slip on asperities depending on size and numbers (e.g., DALGUER et al., 2004, 2008). Slip distributions for multipleasperity source models (Part a of Fig. 9) are used to generate the initial stress field assuming a constant yield stress and constant sliding friction. We use a linear slip weakening friction law (ANDREws, 1976) with a constant slip weakening distance of $0.4 \mathrm{~m}$. The rupture velocity is fixed at $0.8 V_{\mathrm{s}}$, where $V_{\mathrm{s}}$ is the shear wave velocity of (a)

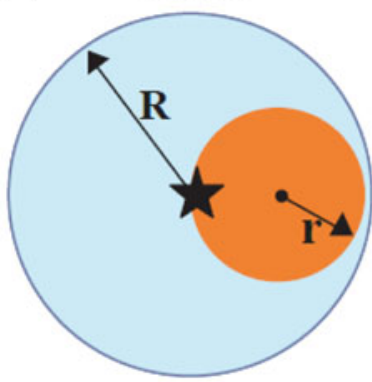

M2EA3

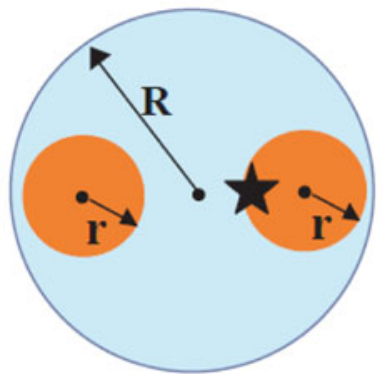

M2DA3

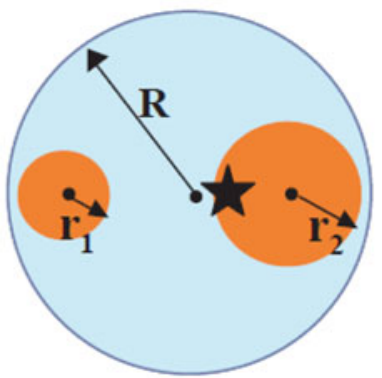

M3EA2

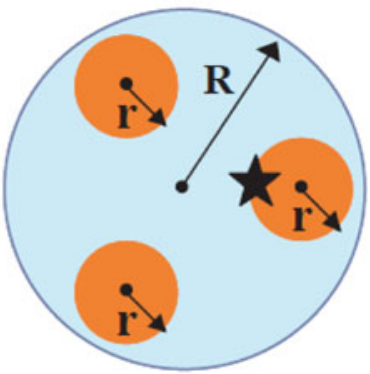

(b)

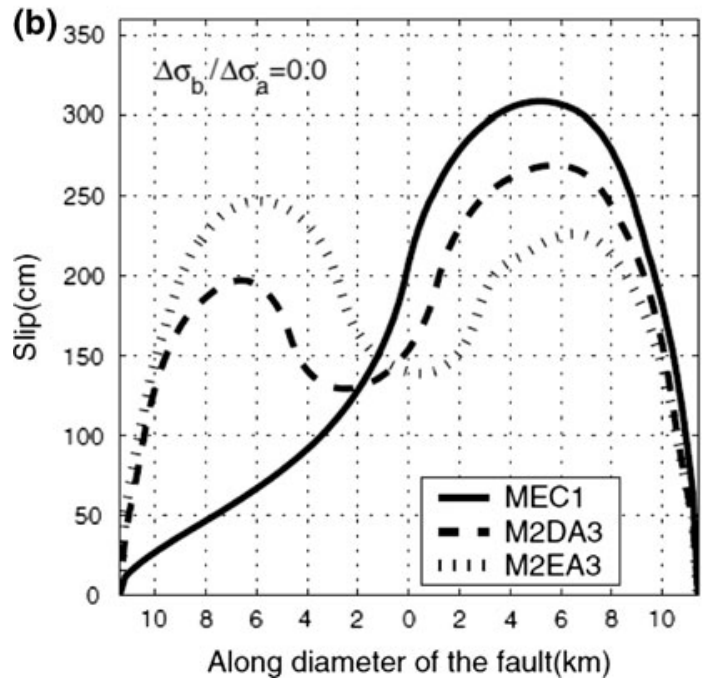

(c)

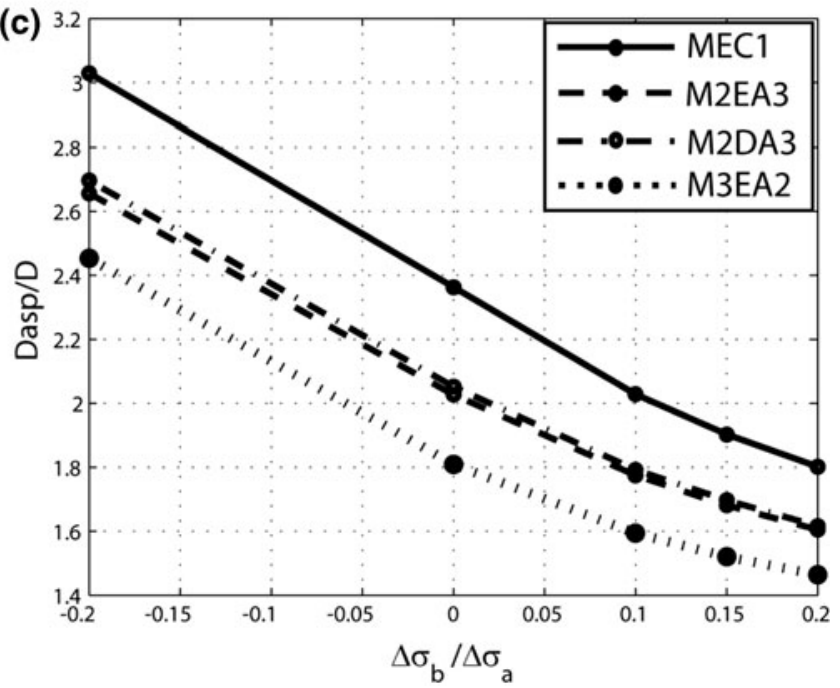

Figure 9

Dynamic solution of three selected circular asperity models with fixed rupture velocity $\left(0.8 V_{\mathrm{s}}\right)$ and critical slip $D_{\mathrm{c}}=0.4 \mathrm{~m}$. a Asperity location for each circular fault model. Star represents the rupture starting point, $R$ and $r$ are the radii of the fault and asperity. The ratio between the combined asperity area $\left(S_{\mathrm{a}}=90 \mathrm{~km}^{2}\right)$ and total rupture area $\left(S=408 \mathrm{~km}^{2}\right)$ is 0.22 . This ratio is partitioned for the double asperities, 11\% for each asperity of model M2EA3 and 6-16\% for M2DA3, and for the triple asperities, 7.3\% for each asperity of model M3EA2. The stress drop in the asperity is $\Delta \sigma_{\mathrm{a}}=10.5 \mathrm{MPa}$. b Final slip distribution along the diameter of the fault (in-plane direction) in the case of $\Delta \sigma_{\mathrm{b}} / \Delta \sigma_{\mathrm{a}}=0$. $\mathbf{c}$ Relationship between average slip $\left(D_{\mathrm{asp}} / D\right)$, versus ration of $\Delta \sigma_{\mathrm{b}} / \Delta \sigma_{\mathrm{a}}$ 
the medium. This problem is solved with the 3D numerical simulation method of DALGUER et al. (2004) that uses the staggered-grid finite-difference code of Pitarka (1999). The problem is solved assuming that the fault is embedded in a whole space. The simulated earthquakes can be considered as self-similar in which the ratios obtained from the slip, slip velocity, and stress drop remain invariant with the size of the fault. Following Madariaga (1979), this assumption is applicable to the multiple asperity model. The ratio between the combined asperity area and total rupture area is equal to 0.22 for all the models (Somerville et al., 1999; DALGUER et al., 2004), which fits the characteristic slip models of recent large earthquakes. The size of total rupture area is $S=400 \mathrm{~km}^{2}$; size of combined-asperity area $S_{\mathrm{a}}=88 \mathrm{~km}^{2}$; stress drop for asperities $\Delta \sigma_{\mathrm{a}}=10.5 \mathrm{MPa}$; stress drop for background area is given as a fraction of the stress drop of the asperities $\Delta \sigma_{\mathrm{b}}=-0.20,0.0,0.10,0.15$ and 0.20 times the $\Delta \sigma_{\mathrm{a}}$; medium is defined by the rigidity $\mu=3.0 \mathrm{GPa}, \mathrm{S}$-wave velocity $V_{\mathrm{s}}=3.2 \mathrm{~km} / \mathrm{s}$, density $\rho=2,800 \mathrm{~kg} / \mathrm{m}^{3}$.

Final slip distribution along the diameter of the fault (in-plane direction) in the case of $\Delta \sigma_{\mathrm{b}} / \Delta \sigma_{\mathrm{a}}=0$ is shown Part b of Fig. 9. Looking at Part c of Figure 9, the simulations show that the ratio of the slip on the asperities to the average slip on the fault $D_{\mathrm{a}} / D$, decreases as a function of the ratio of background stress to asperity stress. Moreover, at a fixed ratio of background to asperity stress, the ratio of the average asperity slip divided by the average slip decreases as the number of asperities increases. Using SomerviLLE et al. (1999) relation that the asperity slip is twice the average slip, we can conclude that the kinematic scaling models fit the dynamic models when the ratios of stress drop is in the band of $-0.05<\Delta \sigma_{\mathrm{b}}$ / $\Delta \sigma_{\mathrm{a}}<0.10$ corresponding $\Delta \sigma_{\mathrm{b}} / \Delta \sigma_{\mathrm{a}} \approx-0.05$ for three asperities, $\Delta \sigma_{\mathrm{b}} / \Delta \sigma_{\mathrm{a}} \approx 0.0$ for two asperities, and $\Delta \sigma_{\mathrm{b}} / \Delta \sigma_{\mathrm{a}} \approx 0.1$ for one asperity.

\section{Recipe for Characterizing Earthquake Source Fault}

The procedure for making the source model is summarized as a recipe of predicting strong ground motions for future large earthquakes. The main features of the source model are characterized by the three kinds of source parameters, outer, inner, and extra fault parameters. Those parameters are estimated one after another with the following steps.

\subsection{Outer Fault Parameters-Estimation of Seismic Moment for Possible Earthquake}

\subsubsection{Step 1: Total Rupture Area $(S=L W)$}

The total fault length $L$ of the possible earthquake is defined as the sum of the lengths of the fault segments, grouping those simultaneously activated. The fault width $W$ is related to the total fault length before reaching the thickness of the seismogenic zone $W_{\max }$ and saturated at $W_{\max } / \sin \theta$, where $\theta$ is the dip angle.

$$
\begin{aligned}
& W(\mathrm{~km})=L(\mathrm{~km}) \quad \text { for } L<W_{\max } \\
& W(\mathrm{~km})=W_{\max } / \sin \theta(\mathrm{km}) \quad \text { for } L \geq W_{\max }
\end{aligned}
$$

\subsubsection{Step 2: Total Seismic Moment $\left(M_{0}\right)$}

The total seismic moment is estimated from the relationship between the seismic moment and rupture area (Fig. 6).

$$
\begin{gathered}
S\left(\mathrm{~km}^{2}\right)=2.23 \times 10^{-15} \times\left(M_{0}(\mathrm{Nm}) \times 10^{7}\right)^{2 / 3} \\
\quad \text { for } M_{0}<7.5 \times 10^{18} \\
S\left(\mathrm{~km}^{2}\right)=4.24 \times 10^{-11} \times\left(M_{0}(\mathrm{Nm}) \times 10^{7}\right)^{1 / 2} \\
\text { for } M_{0} \geq 7.5 \times 10^{18}
\end{gathered}
$$

\subsubsection{Step 3: Average Stress Drop $\left(\Delta \bar{\sigma}_{\mathrm{c}}\right)$ on the Fault}

The average static stress-drop for the rupture area is estimated by Eq. 1 for a circular crack model (EsHeLBY, 1957) at the first stage following $S \propto M_{0}^{1 / 3}$ in Fig. 6, and then by other formulae considering the tectonic loading stress (e.g., FuJII and Matsu'URA, 2000) at the second and third stages respectively following $S \propto$ $M_{0}^{1 / 2}$ and $S \propto M_{0}$ in Fig. 6, to naturally explain the three-stage scaling relationships of the seismic moment and rupture area. 


\subsection{Inner Fault Parameters-Slip Heterogeneity or Roughness of Faulting}

\subsubsection{Step 4: Combined Area of Asperities $\left(S_{a}\right)$}

Two methods are used to determine the combined area of asperities. One is from the empirical relation of $S_{\mathrm{a}}-S$ (SOMERVILle et al., 1999; IriKURA and MiYAKE 2001), where the combined area of asperities is specified to be about $22 \%$. The other is from Eq. 9, which estimates the acceleration level from empirical relations or observed records.

\subsubsection{Step 5: Stress Drop on Asperities $\left(\Delta \sigma_{a}\right)$}

As shown in Eq. $6, \Delta \sigma_{\mathrm{a}}$, as the inner fault parameter, is derived by multiplying $\Delta \bar{\sigma}_{\mathrm{c}}$, as the outer fault parameter, by $S / S_{\mathrm{a}}$ from Step 4 .

\subsubsection{Step 6: Number of Asperities (N)}

The asperities in the entire fault rupture are related to the segmentation of the active faults. The locations of the asperities are assumed from various kinds of information, such as the surface offsets measured along a fault, the back-slip rate found by GPS observations, and the weak reflection coefficients in the fault plane.

\subsubsection{Step 7: Average Slip on Asperities $\left(D_{a}\right)$}

The average slip on asperities is based on Step 6 and the empirical relationships from the quasi-dynamic simulations of the slip distribution for the multipleasperity source model (DALGUER et al., 2004, 2008). (Examples: $D_{\mathrm{a}} / D=2.3$ for $N=1, D_{\mathrm{a}} / D=2.0$ for $N=2, D_{\mathrm{a}} / D=1.8$ for $N=3$ when the stress drop in the background area is assumed zero; see Fig. 9)

\subsubsection{Step 8: Effective Stress on Asperity $\left(\sigma_{a}\right)$ and Background Slip Areas $\left(\sigma_{b}\right)$}

The effective stress $\left(\sigma_{\mathrm{a}}\right)$ on an asperity for strong motion generation is considered to be almost identical to the stress drop on the asperity $\left(\Delta \sigma_{\mathrm{a}}\right)$. The effective stress on a background slip area is constrained by the empirical relationship between the seismic moment and acceleration source spectral level, Eq. 9.

\subsubsection{Step 9: Parameterization of Slip-Velocity Time Functions}

There are several proposals of slip-velocity time functions (e.g., Day, 1982; Nakamura and Miyatake, 2000; Guatteri et al., 2004; Tinti et al., 2005, Liu et al., 2006). We adopted the formulation of NAKAMura and Miyatake (2000). The Kostrov-like slipvelocity time functions are assumed to be functions of the peak slip-velocity and risetime based on the dynamic simulation results of DAY (1982). The peak slip-velocity is given as the effective stress, rupture velocity, and $f_{\max }$.

\subsection{Extra Fault Parameters-Propagation Pattern of Rupture}

The extra fault parameters of the rupture starting point and rupture velocity are used to characterize the rupture propagation pattern in the fault plane. For inland crustal earthquakes, the rupture nucleation and termination are related to the geomorphology of the active faults (e.g., NaKATA et al., 1998; KAME and Yamashita, 2003). However, we have little knowledge and insufficient justification to fix the rupture's starting point. Thus, we just suggest examples of rupture starting points at each asperity as shown in Fig. 10 for the cases of strike-slip (left) and dip-slip faults (right), based on the rupture processes found by inversion of strong motion data.

\section{Verification of the "Recipe"}

The "recipe" proposed here was applied to the creation of deterministic seismic-hazard maps for specific seismic source faults that have a high probability of earthquake occurrence according to the National Seismic Hazard Maps for Japan (2005) by the Earthquake Research Committee (2005). The distributions of ground shaking levels, such as the PGV and seismic intensity, were evaluated for inland crustal earthquakes and subduction earthquakes selected from the viewpoints of impacts and importance of 

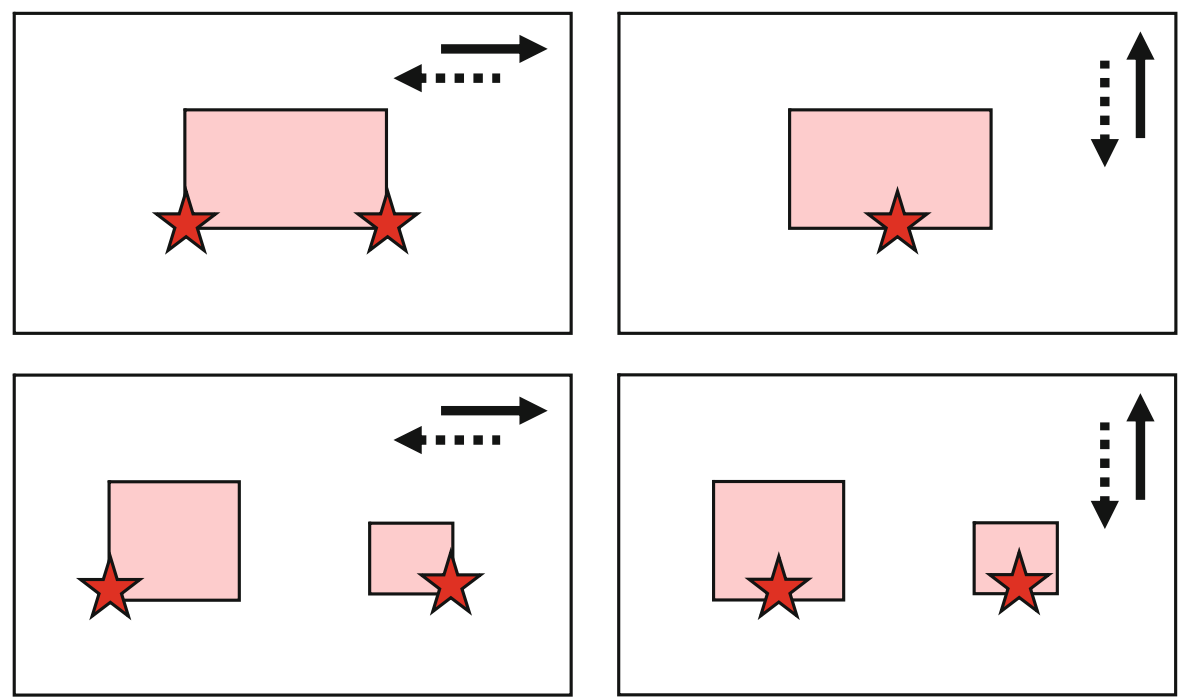

Figure 10

Examples for settings of rupture starting points and asperities for strike-slip (left) and dip-slip faults (right)

earthquake disasters. The applicability of the "recipe" was tested in each case by a comparison between the PGVs of the synthesized motions and those derived from the empirical attenuation relationship by SI and Midorikawa (1999).

A more detailed examination has been attempted to show the validity and applicability of the "recipe" by comparing simulated ground motions with those observed for inland crustal earthquakes and subduction earthquakes. We introduce two examples of inland crustal earthquakes, the 1995 Kobe and 2005 Fukuoka earthquakes.

\subsection{Kobe Earthquake}

The 1995 Kobe, Japan, earthquake $\left(M_{\mathrm{w}} 6.9\right)$ on 17 January 1995 occurred beneath the Awaji and Kobe region in Japan, and caused significant damage and loss. The source slip model of this earthquake was determined from the inversion of strong ground motion data by several researchers (e.g., YoshidA et al., 1996; SEKiguchi et al., 2000). The slip distributions on the fault plane were roughly similar to each other, although there were clear differences based on the frequency range of the data, the smoothing techniques used, etc. Even if the inverted source model was not uniquely determined, a model is not always available to be used as a starting point for strong motion simulation. Moreover, the waveform inversion is usually done using only long-period motions of more than one-second. Therefore, the slip model by the inversion might not be useful for broadband motions that include short-period motions of less than $1 \mathrm{~s}$, which are of interest to engineers.

Thus, for broadband ground motions, we consider the slip model for the Kobe earthquake derived from forward modeling using the empirical Green's function method (KamaE and IrIKura, 1998). Their model consists of three segments, two on the Kobe side and one on the Awaji side (Fig. 11a). The outer parameters include a total rupture area of $51 \times 20.8 \mathrm{~km}^{2}$ and total seismic moment of $3.29 \times 10^{19} \mathrm{MPa}$, with a $\Delta \bar{\sigma}_{\mathrm{c}}$ of $2.3 \mathrm{MPa}$, after following Steps 1, 2, and 3 in the "recipe". Next, the inner fault parameters were: $S_{\mathrm{a}} / S$ of $0.22, \Delta \sigma_{\mathrm{a}}$ of $10.5 \mathrm{MPa}$, with three asperities and the other parameters determined by following Steps 4 through 9 in the 'recipe'. The stress drop for the background area was estimated to be about 4.0 $\mathrm{MPa}$ from the difference between the stress drop of the asperity from Eqs. 6, 8 and 9 that make use of the empirical relation between acceleration spectral level and seismic moment. The source parameters are summarized in Fig. 11b. Model 4 is parameterized following the recipe, indicating the effective stress drop of the background area of $4 \mathrm{MPa}$. To validate contributions of ground motions from the asperities, 
(a)

\begin{tabular}{|ll|c|r|c|r|c|}
\hline & \multicolumn{1}{|c|}{$\begin{array}{c}\mathrm{M}_{0} \\
(\mathrm{Nm})\end{array}$} & $\begin{array}{c}\mathrm{S} \\
\left(\mathrm{km}^{2}\right)\end{array}$ & $\begin{array}{c}\mathrm{D} \\
(\mathrm{m})\end{array}$ & $\begin{array}{c}\Delta \sigma \\
(\mathrm{MPa})\end{array}$ & $\begin{array}{c}\mathrm{A} \\
\left(\mathrm{Nm} / \mathrm{s}^{2}\right)\end{array}$ \\
\hline total fault area & $3.29 \times 10^{19}$ & 1062 & 1.03 & 2.3 & $1.70 \times 10^{19}$ \\
\hline segment 1 & (total) & $8.43 \times 10^{18}$ & 300 & 0.94 & 2.3 & $9.03 \times 10^{18}$ \\
& (asperity) & $3.57 \times 10^{18}$ & 64 & 1.86 & 10.5 & $7.29 \times 10^{18}$ \\
& (background) & $4.86 \times 10^{18}$ & 236 & 0.69 & 4.0 & $5.33 \times 10^{18}$ \\
\hline segment 2 & (total) & $1.60 \times 10^{19}$ & 462 & 1.15 & 2.3 & $1.12 \times 10^{19}$ \\
& (asperity) & $6.96 \times 10^{18}$ & 100 & 2.32 & 10.5 & $9.12 \times 10^{18}$ \\
& (background) & $9.04 \times 10^{18}$ & 362 & 0.83 & 4.0 & $6.50 \times 10^{18}$ \\
\hline segment 3 & (total) & $8.43 \times 10^{18}$ & 300 & 0.94 & 2.3 & $9.03 \times 10^{18}$ \\
& (asperity) & $3.57 \times 10^{18}$ & 64 & 1.86 & 10.5 & $7.29 \times 10^{18}$ \\
& (background) & $4.86 \times 10^{18}$ & 236 & 0.69 & 4.0 & $5.33 \times 10^{18}$ \\
\hline
\end{tabular}

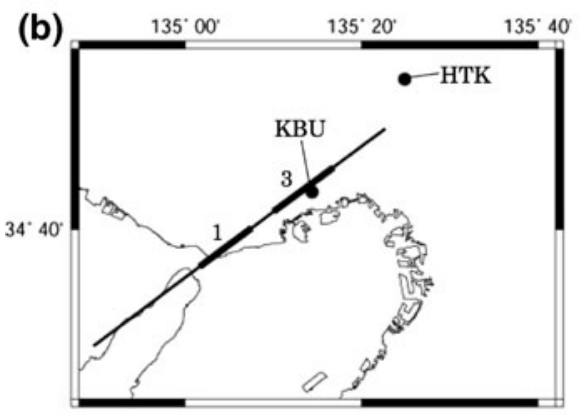

(c)

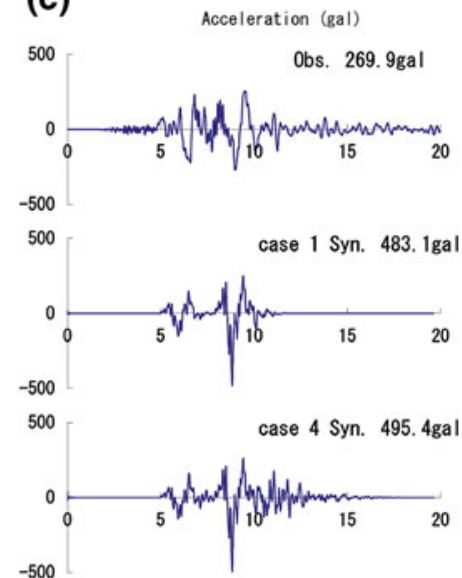

Velocity $(\mathrm{cm} / \mathrm{sec})$

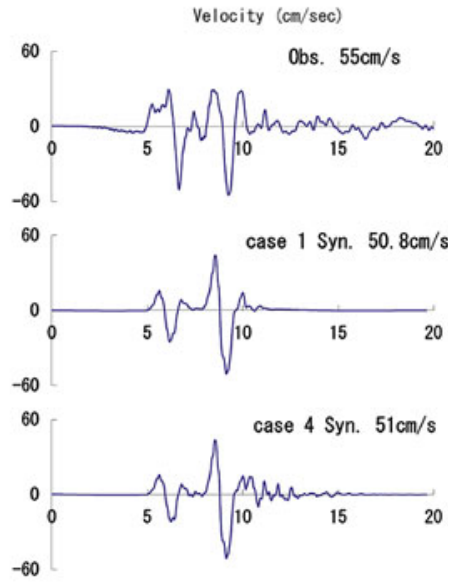

(d)

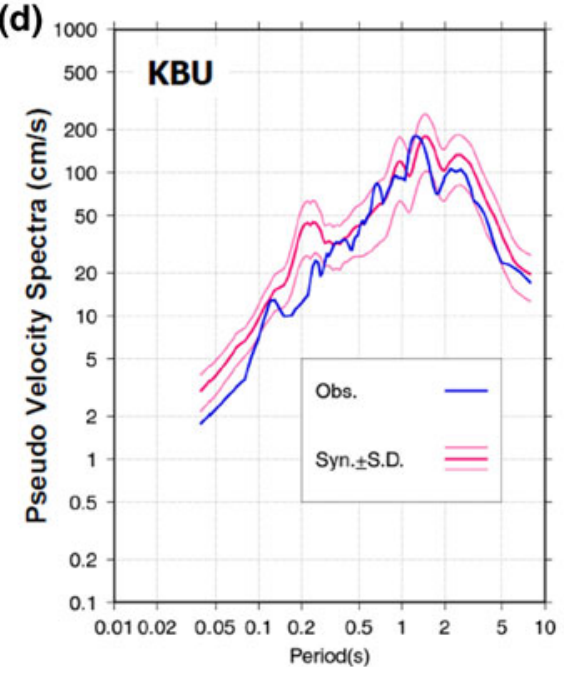

Figure 11

Ground motion simulation for the 1995 Kobe earthquake using the stochastic Green's function method. a Source parameters for synthetic motions. b Characterized source model based on KAMAE and IRIKURA (1998). c Comparison between observed and synthetic particle velocities of NS component at KBU station. d Variability of synthetic pseudo-velocity response spectra using 10 trials of stochastic Green's functions 
we tested a decreased effective stress drop decreasing to 4-0 MPa (Model 1).

The strong ground motions were calculated using the stochastic Green's function method (KAMAE et al., 1998). In this method, the Green's functions of subfaults are stochastically calculated based on bandlimited-white-noise with spectra following the omega-square model (Boore, 1983), then the stochastic Green's functions are summed over the fault using the same formulation of the empirical Green's function method of IRIKURA (1986) and IRIKURA and KAMAE (1994). Site effects are empirically estimated from the observation records for small events. Figure 11c compares the synthesized acceleration and velocity motions for Models 1 and 4 with the observed motions at KBU, which was close to the source fault. From the comparison between velocity ground motions at KBU of Models 1 and 4, most ground motions are mainly controlled by parameterization of asperities, however some differences are seen in the overall duration due to different parameters for background area. The right side of Fig. 11c shows that there was a very good fit between the synthesized and observed velocity motions, both of which have two significant directivity pulses caused by two asperities in the forward rupture direction. The rupture directivity pulses are seen at other stations as well (e.g., Kamae et al., 1998; IrIKURA et al., 2002). We found that the most important parameters for the strong ground motions were the sizes of the asperities and the effective stress on each asperity, which characterize the amplitudes and periods of the directivity pulses causing earthquake damage. On the other hand, the left side of Fig. 11c shows that the synthesized acceleration motions had peaks larger than the observed ones. There are several possibilities that might explain the overestimation of the ground acceleration. One is that a uniform rupture velocity might cause the directivity effect from an asperity near KBU to be too strong. The other possibility is non-linear behavior of surface soil layers might have attenuated high frequency components of the observed acceleration.

The variability of the synthesized pseudo-velocity response spectra calculated with 10 trials of the stochastic Green's functions is shown with the observed ones in Fig. 11d. The observed spectra lie within one standard deviation for periods longer than $0.2 \mathrm{~s}$, the periods that are effective for measuring seismic intensity. The overprediction at $0.3 \mathrm{~s}$ in Fig. $11 \mathrm{~d}$ is unbiased among the 10 trials. The reason is because an artificial periodicity at $0.3 \mathrm{~s}$ is generated by the summation of ground motions from the subfaults of identical size. To avoid the periodicity, IRIKURA and KAMAE (1994) proposed to include the variability of rupture velocity. The large deviations of the synthesized motions at higher frequencies coincide with the overestimation of the acceleration motions. We found that the strong ground motions from the Kobe earthquake calculated using the "recipe" were practical for predicting the distribution of the seismic intensity.

\subsection{Fukuoka Earthquake}

The 2005 Fukuoka earthquake $\left(M_{\mathrm{w}} 6.6\right)$ on 20 March 2005 occurred west off the Fukuoka peninsula, Japan. The fault plane, projected to the surface, and strong motion stations are shown in Fig. 12. The slip model of this earthquake was also determined from the inversion of strong ground motion records by several investigators (e.g. KoBAyashi et al., 2006; SeKiguchi et al., 2006; Asano and Iwata, 2006). The slip distributions were roughly similar to each other

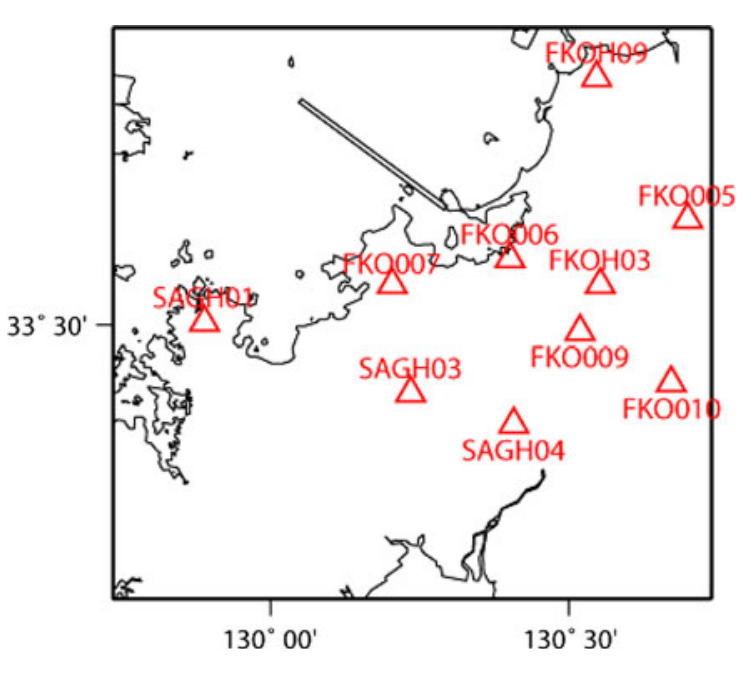

Figure 12

Map showing the fault plane for the 2005 Fukuoka earthquake (rectangular) and the locations of strong motion stations (K-NET and KiK-net) used for analysis (triangles) (after EARTHQUAKE Research CommitteE, 2007) 

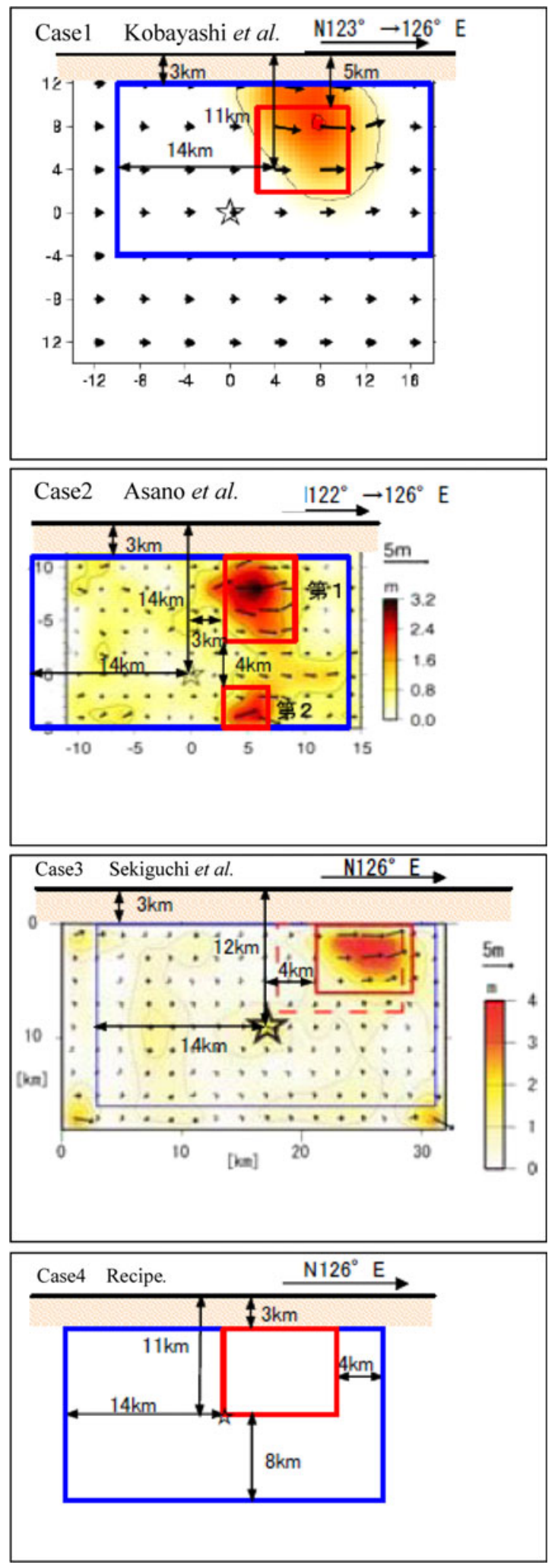

Figure 13

Four characterized source models (Cases 1, 2, 3, 4) with asperities inside the rupture area. Cases 1-3 are derived from waveform inversion results by Kobayashi et al. (2006), Asano and Iwata (2006), and SeKIGUCHI et al. (2006), respectively. Case 4 is a source model based on the "recipe" (after EarthQuaKe Research Committee, 2007)

although there were some differences depending on frequency ranges of the data, smoothing techniques, etc.

Verification of estimating strong ground motions for this earthquake based on the "recipe" was made by the Subcommittee for Evaluations of Strong Ground Motion, Earthquake Research Committee (2007). We describe the outline of the verification mentioned above. The characterized source model with asperities inside the rupture area was used to simulate broadband motions including short-period motions less than $1.0 \mathrm{~s}$ for accurate estimation of not only PGA, PGV, seismic intensity but also response spectra that are of engineering interest. The asperities are defined as rectangular regions where the slip exceeds 1.5 time of the average slip over the fault (see Somerville et al., 1999).

Four characterized models were made to simulate broadband ground motions as shown in Fig. 13. Three source models, Cases 1, 2, and 3 were based on slip models of Kobayashi et al. (2006), SeKiguchi et al. (2006), Asano and Iwata (2006), respectively. Another source model, Case 4, is made following the "recipe". In Case 4 the locations of the three asperities are based on the results from the slip distributions found by inversion of strong motion data. The combined areas of asperities and the stress parameters for the inverted source models are 48$64 \mathrm{~km}^{2}$ and $20-26 \mathrm{MPa}$, while those of the recipe model are $80 \mathrm{~km}^{2}$ and $16 \mathrm{MPa}$, respectively. Compared to the guidelines in the recipe model, the asperity area is a little larger and the stress parameter is little smaller.

The ground motions were simulated using a hybrid method (IrIKURA and Kamae, 1999) with the crossover period of $1.0 \mathrm{~s}$ : in this method one sums the longer period motions calculated numerically assuming a velocity structured while the shorter period 
motions are evaluated using the stochastic Green's function method. Velocity waveforms simulated at engineering bed rock for Case 4 (the "recipe" model) are compared with the observations at 10 sites (Fig. 14). We found that the calculated motions agree well with the observed records, although the calculated motions at some sites are a little smaller because the effects of surface geology were not considered. The observed and calculated PGV for Case 3 (a model derived from inversion) and Case 4 (the "recipe" model) are compared in Fig. 15. Correlation between calculated and observed PGV for Case 4 is 0.77, while that for Case 3 is 0.74 . Overall the characterized source models, based on the "recipe", do well in simulating ground motions from an earthquake (MoRIKAwa et al., 2010).

There are still many other problems to solve in order to apply the "recipe" to inland crustal earthquakes. One of the difficulties is specifying the number of asperities and their locations when no historical records exist. The other problems come from the lack of information about shallow geology beneath the sites and deep velocity structure between the source areas and the sites.

\section{Conclusions}

A "recipe" for predicting the strong ground motions from future crustal earthquakes was constructed based on recent findings from earthquake source physics in seismology and structural damage mechanisms in earthquake engineering. Two scaling relationships have been deduced from the source process those were derived from waveform inversions of strong motion data. The first was the scaling of seismic moment $M_{0}$ versus the entire source area $S$-outer fault parameters; the second was the scaling of seismic moment $M_{0}$ versus asperity areas $S_{\mathrm{a}}$ inner fault parameters.

The characterized source model was defined by three kinds of parameters-outer, inner, and extra fault parameters-following the "recipe" based on scaling relationships. In this study, the validity and applicability of the procedures for characterizing the earthquake sources based on the "recipe" were examined by comparing the observed records and broadband simulated motions for the 1995 Kobe and 2005 Fukuoka earthquakes.

The ground motions synthesized by following the "recipe" for the 1995 Kobe earthquake were consistent with the observations for the velocity and seismic intensity, but the acceleration was overestimated. The most important parameters for the strong ground motions were the sizes of the asperities and the effective stress on each asperity. These two parameters have a strong effect on the amplitudes and periods of directivity pulses that contribute significantly to earthquake damage.

The ground motions of the 2005 Fukuoka earthquake were successfully simulated based on the "recipe," showing good agreement between the observed and synthetic spatial patterns of PGVs, as well as for the waveforms. However, we need a priori information in order to specify the number of asperities, their locations and the location and geometry of the causative fault. It is very difficult to specify such source parameters when no historical records exist. Therefore, we pointed out the importance of modeling the pattern of rupture nucleation and termination-the extra fault parameters-using the information from active faults.

The above two applications to crustal earthquakes demonstrate that the "recipe" is a viable approach for quantitative source modeling that can produce realistic ground motions from future earthquake scenarios.

\section{Acknowledgments}

This study was conducted for long years in collaboration with Katsuhiro Kamae, Tomotaka Iwata, Takao Kagawa, Ken Miyakoshi, and Luis A. Dalguer. We express deep thanks to the Earthquake Research Committee in Japan for allowing us to refer the results and figures of the National Seismic Hazard Maps. We also appreciate the National Research Institute for Earth Science and Disaster Prevention for providing K-NET and KiK-net data. We thank Ralph Archuleta and anonymous reviewers for constructive comments. This work has been performed through the support given to our research projects over years, including the Grants-in-Aids for Scientific 

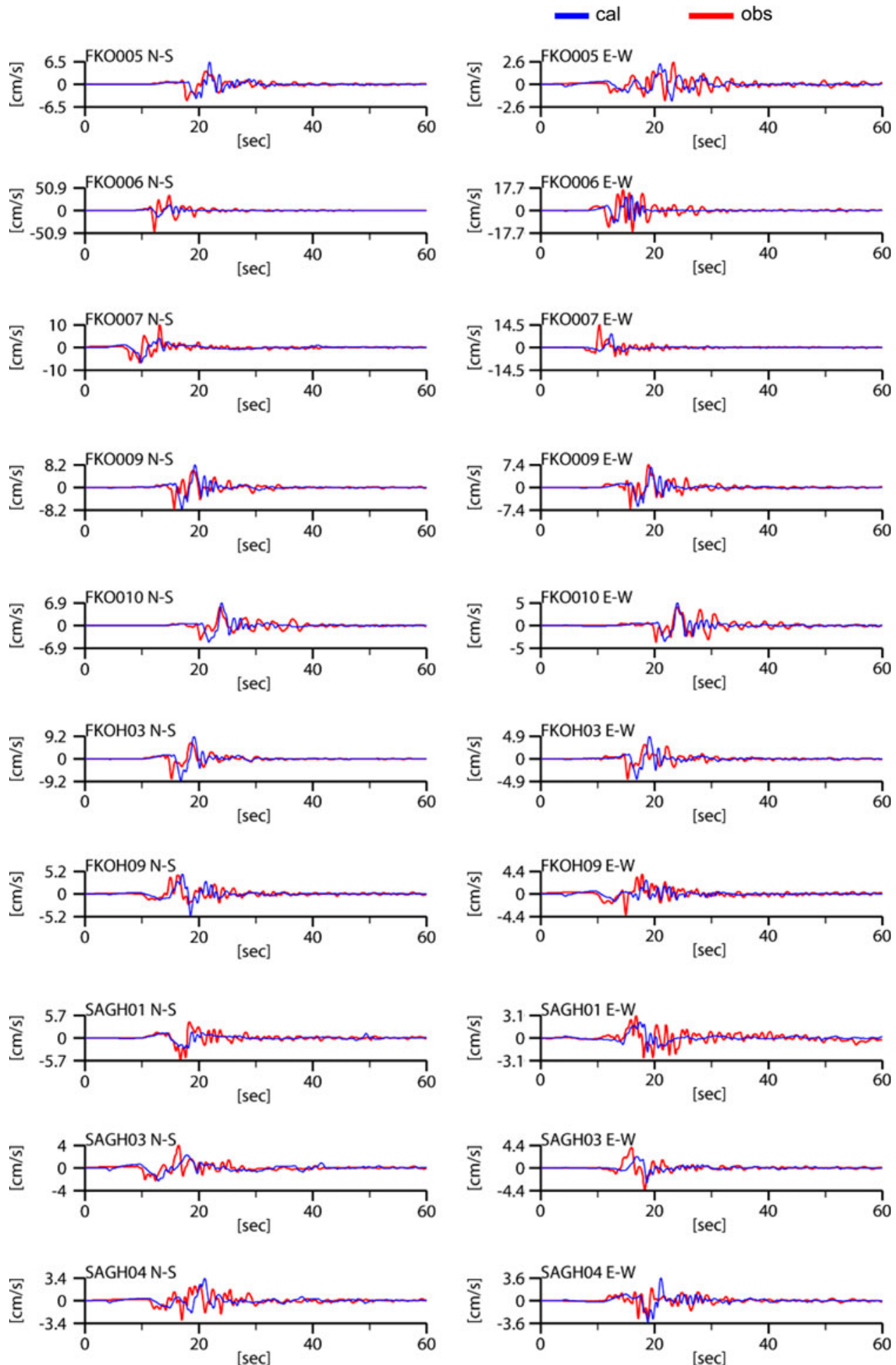

Figure 14

Comparison between observed (red) and simulated (blue) ground velocities on the engineering bedrock for Case 4 by the 'recipe' (after Earthquake Research Committee, 2007) 

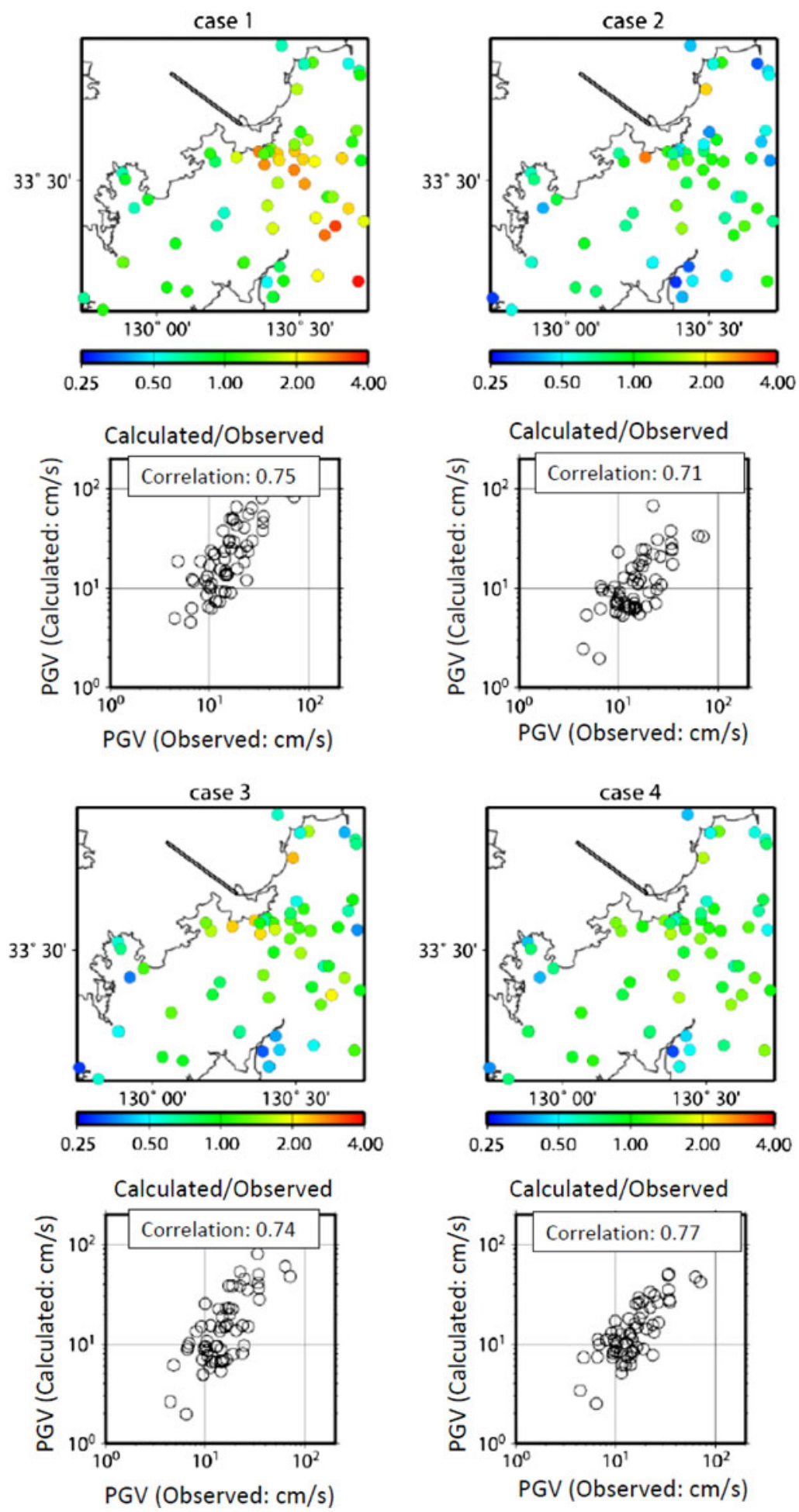

Figure 15

Comparison of observed and calculated PGVs for the 2005 Fukuoka earthquake. The ratios of calculated to observed PGVs for Cases 1 and 2 are plotted in upper left and upper right maps, respectively. Correlations between calculated and observed PGVs for Cases 3 and 4 are shown in lower left and lower right panels, respectively (after EARTHQUAKE RESEARCH COMMITTEe, 2007) 
Research (P.I.: Kojiro Irikura, Grant number: 20310106) from the Japan Society for the Promotion of Science, the Special Project for Earthquake Disaster Mitigation in Urban Areas from the Ministry of Education, Culture, Sports, Science and Technology of Japan, and the Special Coordination Funds for Promoting Science and Technology from the Japan Science and Technology Agency.

Open Access This article is distributed under the terms of the Creative Commons Attribution Noncommercial License which permits any noncommercial use, distribution, and reproduction in any medium, provided the original author(s) and source are credited.

\section{REFERENCES}

ANDREws, D. J. (1976), Rupture velocity of plane-strain shear cracks, J Geophys Res 81, 5679-5687.

Asano, K., and Iwata, T. (2006), Source process and near-source ground motions of the 2005 West Off Fukuoka Prefecture earthquake, Earth Planets Space 58, 93-98.

Asano, K., Iwata, T., and IrikuRa, K. (2005), Estimation of source rupture process and strong ground motion simulation of the 2002 Denali, Alaska, earthquake, Bull Seismol Soc Am 95, 17011715.

Boatwright, J. (1988), The seismic radiation from composite models of faulting, Bull Seismol Soc Am 78, 489-508.

Boore, D. M. (1983), Stochastic simulation of high-frequency ground motions based on seismological models of the radiated spectra, Bull Seismol Soc Am 73, 1865-1894.

Dalguer, L. A., Miyake, H., and Irikura, K. (2004), Characterization of dynamic asperity source models for simulating strong ground motions, Proceedings of the 13th World Conference on Earthquake Engineering No. 3286.

Dalguer, L. A., Miyake, H., Day, S. M., and Irikura, K. (2008), Surface rupturing and buried dynamic-rupture models calibrated with statistical observations of past earthquakes, Bull Seismol Soc Am 98, 1147-1161.

Dan, K., Watanabe, M., Sato, T., and IshiI, T. (2001), Shortperiod source spectra inferred from variable-slip rupture models and modeling of earthquake fault for strong motion prediction, $\mathrm{J}$ Struct Constr Eng AIJ 545, 51-62.

Das, S., and Kostrov, B. V. (1986), Fracture of a single asperity on a finite fault, In Earthquake Source Mechanics (Geophysical Monograph 37, Maurice Ewing Series 6, American Geophysical Union) pp. 91-96.

DAY, S. M. (1982), Three-dimensional simulation of spontaneous rupture: the effect of nonuniform prestress, Bull Seismol Soc Am $88,512-522$.

Earthquake Research Committee (2005), National Seismic Hazard Map for Japan (2005), In Report published by the Headquarters of Earthquake Research Promotion under the Ministry of Education, Culture, Sports, Science, and Technology, 121 pp. (in Japanese).

EARTHQuake Research CommitteE (2007). Validation of the Recipe for Strong Ground Motion Prediction based on the Observed
Records for the 2005 Fukuoka Earthquake, In Midterm Report published by the Headquarters of Earthquake Research Promotion under the Ministry of Education, Culture, Sports, Science, and Technology, 37 pp. (in Japanese).

Eshelby, J. D. (1957), The determination of the elastic field of an ellipsoidal inclusion, and related problems, Proc Roy Soc A241, 376-396.

FuJII, Y., and MATSU'URA, M. (2000), Regional difference in scaling laws for large earthquakes and its tectonic implication, PAGEOPH 157, 2283-2302.

Guatteri, M., Mai P. M., and Beroza, G. C. (2004), A pseudodynamic approximation to dynamic rupture models for strong ground motion prediction, Bull Seismol Soc Am 94, 2051-2063.

HANKs, T. C., and BAKUN, W. H. (2002), A bilinear source-scaling model for M-logA observations of continental earthquakes, Bull Seismol Soc Am 92, 1841-1846.

IRIKURA, K. (1986), Prediction of strong acceleration motions using empirical Green's function, Proceedings of the 7th Japan Earthquake Engineering Symposium, 151-156.

IRIKURA, K. (2004), Recipe for predicting strong ground motion from future large earthquake, Annuals of Disaster Prevention Research Institute 47A, 25-45 (in Japanese with English abstract).

IrikURA, K., and KamaE, K. (1994), Estimation of strong ground motion in broad-frequency band based on a seismic source scaling model and an empirical Green's function technique, Annali di Geofisica 37, 1721-1743.

IrIKURA, K., and KAMAE, K. (1999), Strong ground motions during the 1948 Fukui earthquake, Zisin 52, 129-150 (in Japanese with English abstract).

Irikura, K. and Miyake, H. (2001), Prediction of strong ground motions for scenario earthquakes, Journal of Geography 110, 849-875 (in Japanese with English abstract).

Irikura K, Miyake, H., Iwata, T., Kamae, K., and Kawabe, H. (2002), Revised recipe for predicting strong ground motion and its validation, Proceedings of the 11th Japan Earthquake Engineering Symposium, 567-572 (in Japanese with English abstract).

Irikura, K., Miyake, H., Iwata, T., Kamae, K., Kawabe, H., and DALGUER, L. A. (2004), Recipe for predicting strong ground motion from future large earthquake, Proceedings of the 13th World Conference on Earthquake Engineering No. 1371.

Kame, N., and Yamashita, T. (2003), Dynamic branching, arresting of rupture and the seismic wave radiation in self-chosen crack path modeling, Geophys J Int 155, 1042-1050.

KAMAE, K., and IrIKURA, K. (1998), Rupture process of the 1995 Hyogo-ken Nanbu earthquake and simulation of near-source ground motion, Bull Seismol Soc Am 88, 400-412.

Kamae, K., Irikura, K., and Pitarka, A. (1998), A technique for simulating strong ground motion using hybrid Green's function, Bull Seismol Soc Am 88, 357-367.

KAnAmori, H., and Anderson, D. L. (1975), Theoretical basis of some empirical relations in seismology, Bull Seismol Soc Am 86, 1073-1095.

Kobayashi, R., Miyazaki, S. and Koketsu, K. (2006), Source processes of the 2005 West Off Fukuoka Prefecture earthquake and its largest aftershock inferred from strong motion and $1-\mathrm{Hz}$ GPS data, Earth Planets Space 58, 57-62.

Koketsu, K., Hikima, K., Miyake, H., Maruyama, T., and Wang, Z. (2008), Source process and ground motions of the 2008 Wenchuan, China, earthquake, Eos Trans AGU 89 (53), Fall Meet Suppl, Abstract S31B-1914. 
Liu, P., Archuleta, R. J., and Hartzell, S. H. (2006), Prediction of broadband ground-motion time histories: Hybrid low/high-frequency method with correlated random source parameters, Bull Seismol Soc Am 96, 2118-2130.

MADARIAGA, R. (1977), High frequency radiation from crack (stress drop) models of earthquake faulting, Geophys J R Astron Soc 51, 625-651.

Madariaga, R. (1979), On the relation between seismic moment and stress drop in the presence of stress and strength heterogeneity, J Geophys Res 84, 2243-2250.

Matsuda, T. (1975), Magnitude and recurrence interval of earthquakes from a fault, Zisin-2 28, 269-283 (in Japanese).

Miyake, H., Iwata, T., and IrikuRa, K. (2001), Estimation of rupture propagation direction and strong motion generation area from azimuth and distance dependence of source amplitude spectra, Geophys Res Lett 28, 2727-2730.

Miyake, H., IwATA, T., and IRIKURA, K. (2003), Source characterization for broadband ground-motion simulation: kinematic heterogeneous source model and strong motion generation area, Bull Seismol Soc Am 93, 2531-2545.

Miуаковні, K. (2002), Source characterization for heterogeneous source model, Chikyu Monthly special issue 37, 42-47 (in Japanese).

Miyakoshi, K., Kagawa, T., Sekiguchi, H., Iwata, T., and Irikura, K. (2000), Source characterization of inland earthquakes in Japan using source inversion results, Proceedings of the 12th World Conference on Earthquake Engineering (CD-ROM).

Morikawa, N., and Fujiwara, H. (2003), Source and path characteristics for off Tokachi-Nemuro earthquakes, Programme and Abstracts for the Seismological Society of Japan, 2003 Fall Meeting P104 (in Japanese).

Morikawa, N., Senna, S., Hayakawa, Y., and Fujiwara, H. (2010), Shaking maps for scenario earthquakes by applying the upgraded version of the strong ground motion prediction method "Recipe", PAGEOPH. doi:10.1007/s00024-010-0147-4.

NakamuRa, H., and Miyatake, T. (2000), An approximate expression of slip velocity time functions for simulation of near-field strong ground motion, Zisin 53, 1-9 (in Japanese with English abstract).

Nakata, T., Shimazaki, K., Suzuki, Y., and Tsukuda, E. (1998), Fault branching and directivity of rupture propagation, Journal of Geography 107, 512-528 (in Japanese with English abstract).

PITARKA, A. (1999), 3D elastic finite-difference modeling of seismic motion using staggered grids with nonuniform spacing, Bull Seismol Soc Am 89, 54-68.
SАтон, T. (2004), Short-period spectral level of intraplate and interplate earthquakes occurring off Miyagi prefecture, J Jpn Assoc Earthq Eng 4, 1-4 (in Japanese with English abstract).

Scholz, C. H. (1982), Scaling laws for large earthquakes: consequences for physical models, Bull Seismol Soc Am 72, 1-14.

Scholz, C. H. (2002), The Mechanics of Earthquakes and Faulting (Cambridge University Press).

Sekiguchi, H., IrikuRa, K., and Iwata, T. (2000), Fault geometry at the rupture termination of the 1995 Hyogo-ken Nanbu earthquake, Bull Seismol Soc Am 90, 974-1002.

Sekiguchi, H., Aoi, S., Honda, R., Morikawa, N., Kunugi, T., and FujIwara, H. (2006), Rupture process of the 2005 west off Fukuoka prefecture earthquake obtained from strong motion data of K-NET and KiK-net, Earth Planets Space 58, 37-43.

Si, H., and Midorikawa, S. (1999), New attenuation relationships for peak ground acceleration and velocity considering effects of fault type and site condition, J Struct Constr Eng AIJ 523, 63-70 (in Japanese with English abstract).

SHIMAZAKI, K. (1986), Small and large earthquake: the effects of thickness of seismogenic layer and the free surface, In Earthquake Source Mechanics (AGU Monograph 37, Maurice Ewing Ser. 6 (eds. Das, S., Boatwright, J., and Scholz, C. H.) 209-216.

Somerville, P., Irikura, K., Graves, R., Sawada, S., Wald, D., Abrahamson, N., Iwasaki, Y., Kagawa, T., Smith, N., and KowADA, A. (1999), Characterizing earthquake slip models for the prediction of strong ground motion, Seismol Res Lett 70, 59-80.

Subcommittee for Evaluations of Strong Ground Motion, EARTHQUAKE RESEARch COMMITTEE (2007), Verification of strong motion evaluation using observed records of the 2005 Fukuokaken Seiho-oki Earthquake (in Japanese), In Report of Strong Motion Evaluation Research Committee (MEXT, http://www. jishin.go.jp/main/kyoshindo/07mar_fukuoka/index.htm).

Tinti, E., Fukuyama, E, Piatanesi, A., and Cocco, M. (2005), A kinematic source-time function compatible with earthquake dynamics, Bull Seismol Soc Am 95, 1211-1223.

Wells, D. L., and Coppersmith, K. J. (1994), New empirical relationships among magnitude, rupture length, rupture width, rupture area, and surface displacement, Bull Seismol Soc Am 84, 974-1002.

Yoshida, S., Koketsu, K, Shibazaki, B., Sagiya, T., Kato, T., and YoshidA, Y. (1996), Joint inversion of the near- and far-field waveforms and geodetic data for the rupture process of the 1995 Kobe earthquake, J Phys Earth 44, 437-454.

(Received May 2, 2009, revised March 23, 2010, accepted April 5, 2010, Published online May 27, 2010) 